\title{
The Association between Glucose Levels and Hospital Outcomes in Patients with Acute Exacerbations of Chronic Obstructive Pulmonary Disease
}

\author{
Saleh Ahmed*1, Pritam Bordhan², Hasan Imam³, Umme Salma ${ }^{4}$
}

\section{Abstract}

Introduction: Chronic obstructive pulmonary disease (COPD) is the fourth most common cause of death in the world and will become the third most common in a few years. Identification of prognostic factors may lead to improved treatment strategies and clinical outcomes for COPD. To find out the association between glucose levels and hospital outcomes in patients with acute exacerbations of chronic obstructive pulmonary disease. Materials and Methods: This retrospective study was carried out different privet and public hospital in Chandpur. The information reported in this manuscript was collected during three separate projects in the same hospital. The first cohort included 35 COPD patients admitted for an acute exacerbation to a non-ICU bed to determine if there was a relationship between corticosteroid dosage and hyperglycemia. The second cohort included 210 COPD patients with acute exacerbations who were admitted to the MICU to determine factors associated with mortality and LOS. The third cohort included 105 COPD patients who were monitored for re-admission within 30 days after discharge for an acute exacerbation. Results: Mean arterial pressure, hemoglobin, blood urea nitrogen, albumin, nursing home, pleural effusion and intubation were statistically significant $(p<0.05)$ between two group. Intubation had $5.318(95 \%$ CI 2.578 to 11.721$)$ times increase in odds having length of stay. Intubation was significantly associated with length of stay. Conclusion: Mean arterial pressure, hemoglobin, blood urea nitrogen, albumin, nursing home, pleural effusion and intubation were statistically significant between in hospital deaths group and survivors group.

Keywords: Acute exacerbation, Adverse effects, COPD, Corticosteroids.

Number of Tables: 05; Number of References: 23; Number of Correspondence: 03.

*1. Corresponding Author:

Dr. Saleh Ahmed, MBBS, FCPS

Senior Consultant

Department of Medicine

250 Beded General Hospital, Chandpur.

Email:pdrc4006@gmail.com

Mob. 01731190278

2. Pritam Bordhan

Bachelor of Biotechnology (Honours)

University of Technology Sydney (UTS).

3. Dr. Hasan Imam

Assistant Professor

Department of Internal Medicine

Bangabandhu Sheik Mujib Medical University, Dhaka.

4. Dr. Umme Salma

Lecturer

Islami Bank Medical College Hospital, Rajshahi.

\section{Introduction:}

Chronic obstructive pulmonary disease (COPD) is the fourth most common cause of death in the world and will become the third most common in a few years. Acute exacerbation is a frequent event in the natural course of COPD (AECOPD) and is characterized by the acute aggravation of respiratory symptoms such as dyspnea and coughing with or without sputum that require specific treatment regimens ${ }^{1}$.

Identification of prognostic factors may lead to improved treatment strategies and clinical outcomes for COPD. Among acute exacerbation of COPD
(AECOPD) patients, adverse outcomes are associated with lower arterial $\mathrm{pH}$, older age, 2-5 male gender, underlying comorbidities, higher income, ${ }^{2-4}$ disease severity, and in-hospital complications ${ }^{4}$.

Effective management of an acute exacerbation of COPD (AECOPD) requires symptom relief and reducing the risk for subsequent exacerbations. Identification of patients at risk for more complicated hospital courses should facilitate in-patient management, and risk factors for adverse outcomes include lower arterial $\mathrm{pHs}$, older age, male gender, underlying comorbidities, disease severity, and in-hospital complications $^{2}$. Hyperglycemia is associated with poor outcomes in patients with pneumonia, ${ }^{5}$ myocardial infarction, ${ }^{6}$ and stroke but the effect of hyperglycemia on outcomes during AECOPD has not been definitely established.

The outcomes from these episodes depend on the severity of the underlying chronic lung disease, the degree of acute respiratory failure superimposed on the chronic lung disease, comorbidity, and possibly hospital related complications. Hyperglycemia represents an independent risk factor for hospital associated complications and/or mortality in other medical diagnoses, such as stroke and acute myocardial infarction. Recent studies in patients with acute exa-cerbations of COPD demonstrate that hyperglycemia is associated with an increased length of hospital stay, failure of noninvasive ventilation, and/or mortality. Acute stress and medications used with an acute flare, such as glucocorticoids and beta agonists, increase blood glucose levels. The explanation for poor outcomes likely involves an increase in colonization with pathogenic bacteria, acute changes in host defenses, and possibly metabolic disorders related to hyperglycemia and glycosuria.

\section{Materials and Methods:}

This retrospective longitudinal study was carried out different privet and public hospital in Chandpur. The information reported in this manuscript 
was collected during three separate projects in the same hospital. The first cohort included 35 COPD patients admitted for an acute exacerbation to a non-ICU bed to determine if there was a relationship between corticosteroid dosage and hyperglycemia. The second cohort included 210 COPD patients with acute exacerbations who were admitted to the MICU to determine factors associated with mortality and LOS. The third cohort included 105 COPD patients who were monitored for re-admission within 30 days after discharge for an acute exacerbation. This study we included all adult patients with a discharge diagnosis of COPD exacerbation identified by the coders in the Department of Internal Medicine; we excluded patients younger than 18 years and those admitted to an ICU. Data collected included forced expiratory volume in 1 second (FEV1), history of diabetes, blood glucose at admission, peak glucose, and maximum daily dose of corticosteroid. Data collected included the patients' ages, sex, body mass indices (BMI), baseline pulmonary function tests, comorbidities, complete blood counts (CBCs), complete metabolic profiles, albumin levels, initial arterial blood gases, sputum cultures, blood cultures, chest X-rays, Acute Physiology and Chronic Health Evaluation II (APACHE II) scores, confusion, urea, respiratory rate, systolic blood pressure (CURB65) scores, final diagnoses, total duration of hospital stay, and in-hospital mortality. We separated patients into two groups: Group One died during hospitalization and Group Two survived to hospital discharge. The primary outcome in this study was the identification factors associated with increased in-hospital mortality; the secondary outcome was the identification of the factors associated with increased LOS. We separated patients by LOS into four quartiles to identify parameters associated with increased LOS. Descriptive statistics to summarize base line characteristics of patients in all three cohorts. T-tests and Chi square tests were used to analyze differences between patients who died and patients who survived the acute flare. Multivariable logistic regression models were used to determine factors that predicted increased mortality and LOS. T-tests were used to compare highest blood glucose levels in the early re-hospitalization group with the non-early rehospitalization group.

Results:

Table-I: Clinical characteristics of three cohorts.

\begin{tabular}{lccc}
\hline $\begin{array}{l}\text { Clinical } \\
\text { characteristics }\end{array}$ & $\begin{array}{c}\text { Cohort I } \\
(\mathbf{n}=\mathbf{3 5})\end{array}$ & $\begin{array}{c}\text { Cohort II } \\
(\mathbf{n}=\mathbf{2 1 0})\end{array}$ & $\begin{array}{c}\text { Cohort III } \\
(\mathbf{n}=\mathbf{1 0 5})\end{array}$ \\
\hline Male & 26 & 98 & 52 \\
Age (years) & 69.7 & 66.9 & 73.6 \\
Diabetes & 13 & 82 & - \\
FEV 1 (\%) & 48.1 & 43.2 & 27.9 \\
Mortality & - & 11 & 4 \\
LOS (days) & - & 8 & 4 \\
Re-admission & - & - & 14 \\
\hline
\end{tabular}

Cohort I: Glucose levels and corticosteroid dosage

Cohort II: Glucose levels and mortality and LOS

Cohort III: Peak glucose levels and re-admission

The basic clinical characteristics for the three cohorts are summarized
Table-II: Glucose levels in patients with chronic obstructive pulmonary disease often have acute exacerbations.

\begin{tabular}{lccc}
\hline & $\begin{array}{c}\text { Non diabetes } \\
(\mathbf{n}=\mathbf{2 2})\end{array}$ & $\begin{array}{c}\text { Diabetes } \\
(\mathbf{n}=13)\end{array}$ & p value \\
\cline { 2 - 3 } & Mean \pm SD & Mean \pm SD & \\
\hline Initial glucose (mg/dL) & $122.3 \pm 32.1$ & $171.9 \pm 109.7$ & $0.054^{\text {ns }}$ \\
Peak glucose (mg/dL) & $183.2 \pm 50.3$ & $303.1 \pm 111.7$ & $0.001^{\mathrm{s}}$ \\
Change in glucose (mg/dL) & $61.1 \pm 56.8$ & $129.2 \pm 115.5$ & $0.001^{\mathrm{s}}$ \\
\hline
\end{tabular}

$\mathrm{s}=$ significant, $\mathrm{ns}=$ not significant

$\mathrm{p}$ value reached from unpaired t-test

Mean peak glucose was found $183.2 \pm 50.3 \mathrm{mg} / \mathrm{dl}$ in nondiabetic and $303.1 \pm 111.7 \mathrm{mg} / \mathrm{dl}$ in diabetic group. The mean change in glucose was found $61.1 \pm 56.8 \mathrm{mg} / \mathrm{dl}$ in nondiabetic and $129.2 \pm 115.5 \mathrm{mg} / \mathrm{dl}$ in diabetic group. Which were statistically significant $(\mathrm{p}<0.05)$ between two group.

Table-III: Factors associated with mortality in patients admitted to an intensive care unit.

\begin{tabular}{lccc}
\hline & $\begin{array}{c}\text { In hospital deaths } \\
(\mathbf{n}=24)\end{array}$ & $\begin{array}{c}\text { Survivors } \\
(\mathbf{n}=\mathbf{1 8 6})\end{array}$ & P value \\
\cline { 2 - 3 } & Mean \pm SD & Mean \pm SD & \\
\hline Mean arterial pressure (mmHg) & $64.2 \pm 13.8$ & $84.7 \pm 17.9$ & ${ }^{\mathrm{a}} 0.001^{\mathrm{s}}$ \\
Initial PO2 sat (mmHg) & $88.6 \pm 5.7$ & $89.9 \pm 4.8$ & ${ }^{\mathrm{a}} 0.223^{\mathrm{ns}}$ \\
Initial blood sugar (mg/dl) & $162.4 \pm 59.3$ & $142.7 \pm 49.7$ & ${ }^{\mathrm{a}} 0.076^{\mathrm{ns}}$ \\
Hemoglobin (g/dl) & $11.8 \pm 2.7$ & $13.4 \pm 2.1$ & ${ }^{\mathrm{a}} 0.001^{\mathrm{s}}$ \\
Blood urea nitrogen (mg/dl) & $32.6 \pm 22.2$ & $18.5 \pm 9.8$ & ${ }^{\mathrm{a}} 0.001^{\mathrm{s}}$ \\
Albumin (gm/dl) & $3.0 \pm 0.7$ & $3.9 \pm 0.5$ & ${ }^{\mathrm{a}} 0.001^{\mathrm{s}}$ \\
APACHE II score & $23.1 \pm 7.6$ & $11.6 \pm 4.4$ & ${ }^{\mathrm{a}} 0.001^{\mathrm{s}}$ \\
Nursing home & $13(54.2 \%)$ & $16(8.6 \%)$ & ${ }^{\mathrm{b}} 0.001^{\mathrm{s}}$ \\
Pleural effusion & $6(25.0 \%)$ & $15(8.1 \%)$ & ${ }^{\mathrm{a}} 0.009^{\mathrm{s}}$ \\
Intubation & $19(79.2 \%)$ & $72(38.7 \%)$ & ${ }^{\mathrm{a}} 0.001^{\mathrm{s}}$ \\
\hline
\end{tabular}

$\mathrm{s}=$ significant, $\mathrm{ns}=$ not significant

$a_{p}$ value reached from unpaired t-test

$b_{p}$ value reached from chi square test

Mean arterial pressure, hemoglobin, blood urea nitrogen, albumin, nursing home, pleural effusion and intubation were statistically significant $(\mathrm{p}<0.05)$ between two group.

Table-IV: Factors associated with length of stay in patients admitted to an intensive care unit (ICU).

\begin{tabular}{lcc}
\hline & $P$ value & OR (95\%CI) \\
\hline Nursing home & 0.701 & $1.212(0.434-3.352)$ \\
Initial PO2 sat & 0.063 & $0.903(0.874-1.132)$ \\
Albumin & 0.274 & $0.689(0.326-1.334)$ \\
Intubation & 0.001 & $5.318(2.578-11.721)$ \\
Pleural effusion & 0.080 & $2.628(0.789-7.704)$ \\
APACHE II score & 0.953 & $1.00(0.949-1.073)$ \\
\hline
\end{tabular}

Intubation had 5.318 (95\% CI 2.578 to 11.721$)$ times increase in odds having length of stay. Intubation was significantly associated with length of stay. 
Table-V: Comparison of patients with chronic obstructive pulmonary disease (COPD) exacerbations according to early re-hospitalization status.

\begin{tabular}{|c|c|c|c|}
\hline & \multicolumn{2}{|c|}{ Early re-hospitalizations } & \multirow[t]{3}{*}{$P$ value } \\
\hline & $\begin{array}{c}\text { Yes } \\
(n=14)\end{array}$ & $\begin{array}{c}\text { No } \\
(\mathrm{n}=91)\end{array}$ & \\
\hline & $\mathrm{n}(\%)$ & $\mathrm{n}(\%)$ & \\
\hline \multicolumn{4}{|l|}{ Ejection fraction } \\
\hline$<55 \%$ & $5(35.7 \%)$ & $16(17.6 \%)$ & \multirow{2}{*}{${ }^{\mathrm{a}} 0.114^{\mathrm{ns}}$} \\
\hline$\geq 55 \%$ & $9(64.3 \%)$ & $75(82.4 \%)$ & \\
\hline \multicolumn{4}{|l|}{ Diastolic dysfunction } \\
\hline Yes & $6(42.9 \%)$ & $46(50.5 \%)$ & \multirow{2}{*}{${ }^{\mathrm{a}} 0.592^{\mathrm{ns}}$} \\
\hline No & $8(57.1 \%)$ & $45(49.5 \%)$ & \\
\hline \multicolumn{4}{|l|}{ Pulmonary artery pressure } \\
\hline Normal & $10(71.4 \%)$ & $69(75.8 \%)$ & \multirow{4}{*}{${ }^{\mathrm{a}} 0.903^{\mathrm{ns}}$} \\
\hline Mild PAH & $1(7.1 \%)$ & $9(9.9 \%)$ & \\
\hline Moderate PAH & $2(14.3 \%)$ & $8(8.8 \%)$ & \\
\hline Severe PAH & $1(7.1 \%)$ & $5(5.5 \%)$ & \\
\hline \multicolumn{4}{|l|}{ COPD severity } \\
\hline Mild & $1(7.1 \%)$ & $8(8.8 \%)$ & \multirow{5}{*}{${ }^{\mathrm{a}} 0.666^{\mathrm{ns}}$} \\
\hline Moderate & $1(7.1 \%)$ & $9(9.9 \%)$ & \\
\hline Severe & $6(42.9 \%)$ & $24(26.4 \%)$ & \\
\hline Very severe & $4(28.6 \%)$ & $23(25.3 \%)$ & \\
\hline Not done & $2(14.3 \%)$ & $27(29.7 \%)$ & \\
\hline \multicolumn{4}{|l|}{ ProBNP } \\
\hline$<900$ & $7(50.0 \%)$ & $40(44.0 \%)$ & \multirow{4}{*}{${ }^{\mathrm{a}} 0.813^{\mathrm{ns}}$} \\
\hline $901-1800$ & $2(14.3 \%)$ & $8(8.8 \%)$ & \\
\hline$>1800$ & $1(7.1 \%)$ & $12(13.2 \%)$ & \\
\hline Not done & $4(28.6 \%)$ & $31(34.1 \%)$ & \\
\hline Cor pulmonale & $1(7.1 \%)$ & $12(13.2 \%)$ & ${ }^{\mathrm{a}} 0.523^{\mathrm{ns}}$ \\
\hline Beta-blocker use & $3(21.4 \%)$ & $10(11.0 \%)$ & ${ }^{\mathrm{a}} 0.270^{\mathrm{ns}}$ \\
\hline $\begin{array}{l}\text { Long-acting bronchodilators and/or } \\
\text { inhaled corticosteroids }\end{array}$ & $9(64.3 \%)$ & $56(61.5 \%)$ & ${ }^{\mathrm{a}} 0.844^{\mathrm{ns}}$ \\
\hline Coronary artery disease & $5(35.7 \%)$ & $25(27.5 \%)$ & ${ }^{\mathrm{a}} 0.525^{\mathrm{ns}}$ \\
\hline Atrial fibrillation & $0(0.0 \%)$ & $5(5.5 \%)$ & ${ }^{\mathrm{a}} 0.400^{\mathrm{ns}}$ \\
\hline $\begin{array}{l}\text { Abnormal WBC }\left(<4.0 \text { or }>12.0 \times 10^{3}\right. \\
/ \mu \mathrm{L})\end{array}$ & $2(14.3 \%)$ & $19(20.9 \%)$ & ${ }^{\mathrm{a}} 0.445^{\mathrm{ns}}$ \\
\hline Intubation & $1(7.1 \%)$ & $7(7.7 \%)$ & ${ }^{\mathrm{a}} 0.943^{\mathrm{ns}}$ \\
\hline Mean blood glucose (mg/dl) & $186.2 \pm 38.7$ & $209.8 \pm 42.3$ & ${ }^{\mathrm{b}} 0.052^{\mathrm{ns}}$ \\
\hline Mean length of stay (days) & $4.2 \pm 0.8$ & $4.5 \pm 0.9$ & ${ }^{\mathrm{b}} 0.242^{\mathrm{ns}}$ \\
\hline Mean follow-up (days) & $20.2 \pm 3.4$ & $18.4 \pm 4.6$ & ${ }^{\mathrm{b}} 0.121^{\mathrm{ns}}$ \\
\hline
\end{tabular}

ns $=$ not significant

$a_{p}$ value reached from chi square test

$b_{p}$ value reached from unpaired t-test

These patients had 105 admissions, including 14 early rehospitalizations $(13.3 \%)$, defined as a re-hospitalization within 30 days after discharge. The difference were not statistically significant $(\mathrm{p}>0.05)$ between two group.

\section{Discussion:}

In this study observed the mean peak glucose was found $183.2 \pm 50.3 \mathrm{mg} / \mathrm{dl}$ in non- diabetic and $303.1 \pm 111.7 \mathrm{mg} / \mathrm{dl}$ in diabetic group. The mean change in glucose was found $61.1 \pm 56.8 \mathrm{mg} / \mathrm{dl}$ in non- diabetic and $129.2 \pm 115.5 \mathrm{mg} / \mathrm{dl}$ in diabetic group. Which were statistically significant $(p<0.05)$ between two group. Islam et al. ${ }^{8}$ reported that Twenty non-diabetic patients had a mean initial glucose of
$122 \pm 33 \mathrm{mg} / \mathrm{dl}$ with a range of 83 to $238 \mathrm{mg} / \mathrm{dl}$. Six patients had maximum glucose levels above $200 \mathrm{mg} / \mathrm{dl}$. Ten patients with diabetes (DM) had mean initial glucose levels of $196 \pm 110 \mathrm{mg} / \mathrm{dl}$ with a range of 77 to $446 \mathrm{mg} / \mathrm{dl}$, and nine had maximum glucose levels above $200 \mathrm{mg} / \mathrm{dl}$. We stratified the patients into tertiles based on the maximum daily dose of corticosteroids received during hospitalization. There were no differences in the initial or maximum glucose levels in these three groups $(\mathrm{P}>0.05)$ Parappil reviewed 246 episodes of AECOPD $^{9}$. Forty-two percent of the admissions had a random glucose greater than $180 \mathrm{mg} /$ dl, but mean values were not provided. Fifty-three patients $(22 \%)$ had DM. Burt measured glucose values in 47 patients using a continuous monitoring system; the mean level was $137 \pm 34 \mathrm{mg} / \mathrm{dl}^{10}$. The peak levels in their cohort were $220 \pm 61 \mathrm{mg} / \mathrm{dl}$. Seven patients $(15 \%)$ had DM. Chakrabarti studied 88 patients with decompensated COPD (mean $\mathrm{pH}=7.25$ ) who required non-invasive ventilation ${ }^{11}$. Jafar et al. ${ }^{7}$ reported only the highest blood glucose recorded for the patients during their hospital stay was used for analysis, and patients were grouped according to their blood glucose quartile (group $1,<108 \mathrm{mg} / \mathrm{dl}, \mathrm{n}=69$; group 2, 108-125 mg/dl, $\mathrm{n}=69$; group 3, 126-160 mg/dl, $\mathrm{n}=75$; and group $4,>160 \mathrm{mg} / \mathrm{dl}, \mathrm{n}=71)$. The relative risk $(\mathrm{RR})$ of death or a longer inpatient stay was significantly increased in group 3 (RR $1.46,95 \%$ CI 1.05 to $2.02, \mathrm{p}=0.02$ ) and group 4 (RR 1.97, 95\% CI 1.33 to 2.92, p<0.0001) compared to group 1 . For each $18 \mathrm{mg} / \mathrm{dl}$ increase in blood glucose the absolute risk of an adverse outcome increased by $15 \%(95 \% \mathrm{CI} 4 \%$ to $27 \%, \mathrm{p}=0.006)$.

In this study observed that the mean arterial pressure, hemoglobin, blood urea nitrogen, albumin, nursing home, pleural effusion and intubation were statistically significant $(p<0.05)$ between two group. Islam et al. ${ }^{8}$ reported that the majority of excluded patients had congestive heart failure with exacerbation or acute asthma and did not have an AECOPD as the primary diagnosis. Therefore, this study enrolled 217 cases with AECOPD who needed ICU admission; 26 died during hospitalization and 191 survived to hospital discharge. Eighty-nine percent of the patients who died in the hospital had a FEV1 less than $50 \%$ of predicted; $68 \%$ of the survivors had a FEV1 less than $50 \%$ of predicted. The mean initial blood glucose on admission in this cohort was $156 \pm 74.3 \mathrm{mg} / \mathrm{dl}$ (range 60 to $485 \mathrm{mg} / \mathrm{dL}$ ). The overall LOS was $9.01 \pm 6.00$ days. It was $8.37 \pm 4.99$ days in survivors and $13.69 \pm 9.78$ days in non-survivors. Initial mean blood glucose was $156 \pm 74.3 \mathrm{mg} / \mathrm{dl}$ and did not predict a statistically significant increased LOS in univariate logistic regression analysis (OR 1.00; 95\% CI: 0.99-1.01, $\mathrm{P}=0.59$ ). Baker et al. measured glucose levels in 284 patients with acute exacerbations of COPD requiring hospitalization and reported the highest value measured either at admission or during the admission ${ }^{12}$. Glucose levels have a circadian pattern with higher values in the late afternoon in corticosteroid treated patients with AECOPD, and routine morning lab tests may not detect the range of glucose elevations ${ }^{13,14}$. In addition, glycemic variability is associated with increased length of stay and mortality in 
hospitalized patients and needs to be considered in these studies ${ }^{15}$. In-hospital management of hyperglycemia is relatively easy and prevents complications ${ }^{16,17}$. Moretti and colleagues studied 186 patients admitted to a respiratory intensive care unit with respiratory failure characterized by a mean $\mathrm{pH}$ of $7.23 \pm 0.07$ and a mean $\mathrm{PaCO} 2$ of $85.3 \pm 15.8$ $\mathrm{mm} \mathrm{Hg}^{18}$. Krinsley studied the relationship between hyperglycemia and hospital mortality in a heterogeneous group of critically ill patients and concluded that even modest hyperglycemia after intensive care unit admission was associated with a substantial increase in hospital mortality in patients with a wide range of medical and surgical diagnoses ${ }^{19}$.

In current study reported intubation had 5.318 (95\% CI 2.578 to 11.721 ) times increase in odds having length of stay. Intubation was significantly associated with length of stay. Islam et al. ${ }^{8}$ observed multivariable logistic regression including statistically significant mortality risk factors from univariate logistic regression showed that patients who lived in a nursing home (OR 50.02; 95\% CI: 2.7-923.19), had a low hemoglobin (OR 0.40; 95\% CI: 0.17-0.94), were intubated (OR 27.54; 95\%1.78-425.39), and had a high APACHE II score (OR 1.55; 95\% CI: 1.07-2.23) were at increased risk for mortality, but the initial glucose levels were not associated with increased risk. Univariate analysis did demonstrate that nursing home status, low albumin, the presence of a pleural effusion, intubation, and high APACHE II scores were associated with increased LOS (P $<0.05$ for each factor). A multivariable logistic regression model demonstrated that only intubation (OR 5.93; 95\%CI 2.78-12.65) predicted a statistically significant increase in hospital LOS. High intracellular glucose concentrations increase the production of reactive oxygen species, such as superoxide, and of peroxynitrite which can impair mitochondrial function and damage proteins, cellular membranes, and nucleic acids ${ }^{20,21}$. Hyperglycemia causes glycosylation of proteins, impaired leukocyte function, and activation of pro-inflammatory genes through transcription factors $^{20,22}$. Glycosuria potentially causes an osmotic diuresis with a loss of electrolytes and volume contraction which could adversely affect the clinical course. Occasionally, patients on corticosteroids develop hyperglycemic hyperosmolar syndrome or diabetic ketoacidosis. Other studies have reported that hyperglycemia increases the mortality in patients with acute myocardial infarction, with ischemic or hemorrhagic stroke, and with community-acquired pneumonia ${ }^{6,23}$. Parappil et al. ${ }^{9}$ retrospectively analyzed 172 patients admitted with AECOPD, including 39 patients with comorbid diabetes mellitus. In their study the presence of DM was associated with increased length of stay (mean 7.8 days) and mortality (8\%) in comparison with patients without DM (6.5 days and 4\% mortality), but these differences were not statistically significant.

In present study observed that patients had 105 admissions, including 14 early rehospitalizations (13.3\%), defined as a re-hospitalization within 30 days after discharge. The difference were not statistically significant $(p>0.05)$ between two group. Islam et al. ${ }^{8}$ reported these patients had 103 admissions, including 13 early rehospitalizations (12.6\%), defined as a re-hospitalization within 30 days after discharge. The mean peak blood glucose levels were $212 \pm 105 \mathrm{mg} / \mathrm{dl}$ with a range from $94 \mathrm{mg} / \mathrm{dl}$ to $600 \mathrm{mg} / \mathrm{dl}$. There were no differences in mean peak glucose levels between early re-hospitalization and non-early re-hospitalization patients $(\mathrm{P}=0.318)$.

\section{Conclusion:}

Mean arterial pressure, hemoglobin, blood urea nitrogen, albumin, nursing home, pleural effusion and intubation were statistically significant between in hospital deaths group and survivors group. On the frequency and severity of hyperglycemia in these patients, the factors associated with hyperglycemia, the effects of hyperglycemia on short term outcomes.

\section{Conflict of Interest:}

The developments of hyperglycemia introduce practical problems in the management of the patients both in the hospital and after discharge. A number of information was not consistently available in the hospital records. Different physicians were managed the patients and different approaches would influence the choice of medication and dose of medication.

\section{Ackowledgement:}

This is my great pleasure to express profound gratitude to Medicine Today.

\section{References:}

1. Global Initiative for Chronic Obstructive Lung Disease (GOLD). 2011. Global Strategy for the Diagnosis, Management and Prevention of COPD. http://www.goldcopd.org/. Accessed:1 May 2012.

2. Patil SP, Krishnan JA, Lechtzin N, Diette GB. In-hospital mortality following acute exacerbations of chronic obstructive pulmonary disease. Arch Intern Med. 2003; 163(10): 1180-1186.

https://doi.org/10.1001/archinte.163.10.1180

PMid:12767954

3. Groenewegen KH, Schols AM, Wouters EF. Mortality and mortality-related factors after hospitalization for acute exacerbation of COPD. Chest. 2003; 124(2): 459-467.

https://doi.org/10.1378/chest.124.2.459

PMid:12907529

4. Bustamante-Fermosel A, De Miguel-Yanes JM, Duffort-Falco M, Muñoz J. Mortality related factors after hospitalization for acute exacerbation of chronic obstructive pulmonary disease: the burden of clinical features. Am J Emerg Med. 2007; 25(5): 515-522.

https://doi.org/10.1016/j.ajem.2006.09.014

\section{PMid:17543654}

5. McAlister FA, Majumdar SR, Blitz S. The relation between hyperglycemia and outcomes in 2,471 patients admitted to the hospital with community-acquired pneumonia. Diabetes Care. 2005; 28(4):810-5.

https://doi.org/10.2337/diacare.28.4.810

PMid: 15793178 
6. Capes SE, Hunt D, Malmberg K. Stress hyperglycaemia and increased risk of death after myocardial infarction in patients with and without diabetes: a systematic overview. Lancet. 2000; 355(9206): 773-8.

https://doi.org/10.1016/S0140-6736(99)08415-9

7. Jafar N, Edriss H, Islam E, Nugent $K$. The association between blood glucose levels and hospital outcomes in patients admitted with acute exacerbations of chronic obstructive pulmonary disease. The Southwest Respiratory and Critical Care Chronicles. 2014; 2(7): 1-11.

https://doi.org/10.12746/swrecc2014.0207.082

8. Islam EA, Limsuwat C, Nantsupawat T, Berdine GG, Nugent KM. The association between glucose levels and hospital outcomes in patients with acute exacerbations of chronic obstructive pulmonary disease. Ann Thorac Med. 2015; 10: 94-9.

https://doi.org/10.4103/1817-1737.151439

PMid:25829959 PMCid:PMC4375748

9. Parappil A, Depxynski B, Collett P, Marks GB. Effect of comorbid diabetes on length of stay and risk of death in patients admitted with acute exacerbations of COPD. Respirology. 2010; 15: 918-22.

https://doi.org/10.1111/j.1440-1843.2010.01781.x

PMid:20546185

10. Burt MG, Roberts GW, Aguilar-Loza NR, Quinn SJ, Frith PA, Stranks SN. Relationship between glycaemia and length of hospital stay during acute exacerbation of chronic obstructive pulmonary disease. Intern Med J. 2013; 43: 721-4.

https://doi.org/10.1111/imj.12157

PMid:23745995

11. Chakrabarti B, Angus RM, Agarwal S, Lane S, Calverley PM. Hyperglycaemia as a predictor of outcome during non-invasive ventilation in decompensated COPD. Thorax. 2009; 64: 857-62.

https://doi.org/10.1136/thx.2008.106989

PMid:19454410

12. Baker EH, Janaway $\mathrm{CH}$, Philips BJ, Brennan AL, Baines DL, Wood DM, et al. Hyperglycaemia is associated with poor outcomes in patients admitted to hospital with acute exacerbations of chronic obstructive pulmonary disease. Thorax. 2006; 61: 284-9.

https://doi.org/10.1136/thx.2005.051029

PMid:16449265 PMCid:PMC2104606

13. Burt MG, Roberts GW, Aguilar-Loza NR, Frith P, Stranks SN. Continuous monitoring of circadian glycemic patterns in patients receiving prednisone for COPD. J Clin Endocrinol Metab. 2011; 96: 1789-96.

https://doi.org/10.1210/jc.2010-2729

PMid:21411550

14. Roberts GW, Monteiro VE. Pattern of high-dose prednisoloneinduced hyperglycaemia in COPD exacerbations. J Pharm Pract Res. 2009; 39: 50-4.

https://doi.org/10.1002/j.2055-2335.2009.tb00704.x
15. Mendez CE, Mok KT, Ata A, Tanenberg RJ, Calles-Escandon J, Umpierrez GE. Increased glycemic variability is independently associated with length of stay and mortality in non-critically ill hospitalized patients. Diabetes Care. 2013; 36: 4091-7.

https://doi.org/10.2337/dc12-2430

PMid:24170754 PMCid:PMC3836112

16. Kavanagh BP, McCowen MB, McCowen KC. Clinical practice. Glycemic control in the ICU. N Eng J Med 2010; 363: 2540-6.

https://doi.org/10.1056/NEJMcp1001115

PMid:21175316

17. Moghissi ES. Addressing hyperglycemia from hospital admission to discharge. Curr Med Res Opin. 2010; 26: 589-98.

https://doi.org/10.1185/03007990903566822

PMid:20078323

18. Moretti M, Cilione C, Tampieri A, Fracchia C, Marchioni A, Nava S. Incidence and causes of non-invasive mechanical ventilation failure after initial success. Thorax. 2000; 55(10): 819-825.

https://doi.org/10.1136/thorax.55.10.819

PMid:10992532 PMCid:PMC1745609

19. Krinsley JS. Association between hyperglycemia and increased hospital mortality in a heterogeneous population of critically ill patients. Mayo Clin Proc. 2003; 78(12): 1471-148.

https://doi.org/10.4065/78.12.1471

PMid:14661676

20. Clement S, Braithwaite SS, Magee MF, Ahmann A, Smith EP, Schafer RG, et al. American Diabetes Association Diabetes in Hospitals Writing Committee. Management of diabetes and hyperglycemia in hospitals. Diabetes Care. 2004; 27: 553-91.

https://doi.org/10.2337/diacare.27.2.553

PMid:14747243

21. Chaudhuri A, Umpierrez GE. Oxidative stress and inflammation in hyperglycemic crises and resolution with insulin: Implications for the acute and chronic complications of hyperglycemia. J Diabetes Complications. 2012; 26: $257-8$.

https://doi.org/10.1016/j.jdiacomp.2012.04.016

PMid:22658407 PMCid:PMC3718464

22. Nielson CP, Hindson DA. Inhibition of polymorphonuclear leukocyte respiratory burst by elevated glucose concentrations in vitro. Diabetes. 1989; 38: 031-5.

https://doi.org/10.2337/diabetes.38.8.1031

PMid:2753233

23. Umpierrez GE, Isaacs SD, Bazargan N, You X, Thaler LM, Kitabchi AE. Hyperglycemia: An independent marker of in-hospital mortality in patients with undiagnosed diagnosis. J Clin Endocrinol Metab. 2002; 87: 978-82.

https://doi.org/10.1210/jcem.87.3.8341

PMid: 11889147 